\title{
Production and partial characterization of extracellular polysaccharide from endophytic Bacillus cereus RCR 08
}

\author{
Ananya Mukherjee ${ }^{1}$, Rituparna Das ${ }^{1}$, Anju Sharma ${ }^{1}$, Arundhati Pal ${ }^{2}$ and A. K. Paul ${ }^{1 *}$ \\ ${ }^{1}$ Microbiology Laboratory, Department of Botany, University of Calcutta, 35, Ballygunge \\ Circular Road, Kolkata, India \\ ${ }_{2}^{2}$ Post Graduate Department of Botany, Serampore College, 9, William Carey Road, Serampore, Hooghly, India
}

\begin{abstract}
The present study focuses attention on the production of extracellular polysaccharide (EPS) by bacterial endophytes of Ricinus communis L. Among the 28 endophytic bacterial isolates screened for EPS production, a potent isolate identified as Bacillus cereus RCR 08 (GenBank accession number MF159112) produced significant amount of EPS in mineral salts medium under batch culture. In single factor system of analysis, glucose and ammonium chloride were most suitable carbon and nitrogen sources respectively for EPS production. Maximum growth (7.1 g/L) and EPS yield $(10.24 \mathrm{~g} / \mathrm{L})$ was attained when glucose and ammonium chloride were used in the ratio of 25:1. The isolated polymer contained carbohydrate (88.8\%), protein (3.18\%), RNA (6.0\%) as well as DNA (3.2\%) and showed characteristic FTIR absorption spectrum with peaks at $3404,2,933,1,655$, and $1,042 \mathrm{~cm}^{-1}$. The emulsifying activity of the EPS was more or less comparable with Tween 80. Though the EPS failed to show any antibacterial activity, it exhibited moderate DPPH radical scavenging activity and displayed a dose-dependent cytotoxic activity against hepato cellular carcinoma (Huh 7.5) cell line in MTT assay. A detailed physico-chemical analysis is, therefore, essential to assess the significance and potential importance of this endophytic EPS in biotechnology.
\end{abstract}

KEY WORDS: BACILLUS CEREUS, ENDOPHYTIC BACTERIA, EXTRACELLULAR POLYSACCHARIDE, FTIR ANALYSIS, RICINUS COMMUNIS L.

\section{INTRODUCTION}

Endophytes are microorganisms which colonize living internal tissues of plants without causing any apparent negative impact on the host plant. They occur ubiqui-

\section{ARTICLE INFORMATION:}

*Corresponding Author: amalk_paul@yahoo.co.in Received $11^{\text {th }}$ Nov, 2017

Accepted after revision $19^{\text {th }}$ Dec, 2017

BBRC Print ISSN: 0974-6455

Online ISSN: 2321-4007 CODEN: USA BBRCBA

Thomson Reuters ISI ESC and Crossref Indexed Journal

NAAS Journal Score 2017: 4.31 Cosmos IF: 4.006

- A Society of Science and Nature Publication, 2017. All rights reserved.

Online Contents Available at: http//www.bbrc.in/

DOI: $10.21786 / \mathrm{bbrc} / 10.4 / 3$ tously in almost all plants and are benefitted from the host by deriving organic nutrients, shelter as well as transmission to the next host generation. On the other hand endophytes favour the infected host plants by fixation of atmospheric nitrogen, production of growth 
promoting substances, imparting tolerance to stress and toxicity to herbivores, nematodes and pathogens (Borges et al., 2009). Recently, attention has been paid to the endophytes for the production of biopolymers including extracellular polysaccharides (EPS) and their utilization for potential industrial applications (Donot et al., 2012; Kusari et al., 2014).

Microbial extracellular polymeric substances, the heterogenous matrix of polymers comprising of polysaccharides, proteins, nucleic acids, uronic acids, humic substances, lipids etc. (Wingender et al., 1999) are biosynthesized by bacteria and fungi via intracellular or extracellular processes (Freitas et al., 2011). In recent years, a variety of structurally different EPSs with bioactive potentials have been reported from endophytes (Guo et al., 2014; Mahapatra and Banerjee, 2016; Liu et al., 2017 ).

Production of such endophytic EPS in culture depends on media components such as carbon and nitrogen sources, minerals, surfactants and cultivation conditions including incubation temperature, $\mathrm{pH}$ and aeration (Liu et al., 2009). The EPS so produced in their natural habitat play a key role in plant-endophyte interactions and are essential for the survival in the host plant (Wingender et al., 1999). Owing to their interesting physico-chemical and biological activities, the endophytic EPS has been considered as potential candidate for nutraceuticals, bioleaching, bioremediation, waste water treatment and pharmaceutical industries. Special attention has also been paid for the use of EPS as a hydrophilic matrix for controlled release of drugs (Gandhi et al., 1997), anti HIV agent (Yamada et al., 1997), enhancement of nonspecific immunity (Sutherland, 1998), antimicrobial (Orsod et al., 2012), antioxidant (Liu et al., 2009) and antitumour activities (Chen et al., 2013). Furthermore, they have been found to be extremely susceptible for biodegradation in nature and thus are environment friendly.

Ricinus communis L. (Euphorbiaceae), a perennial flowering shrub, is an indigenous oil-yielding plant of India having medicinal as well as agrochemical importance. Its oil and seeds have been used in folk medicine for disorders like severe constipation, worm infestation, rheumatism, intestinal inflammation and also for birth control. Castor oil is an effective motor lubricant and also used as a component of flavour and ingredient for preparing protective coatings for tablets. Apart from these, a range of biologically active compounds have been isolated especially from rhizosphere and endosphere associated fungi of $R$. communis L. with probable industrial applications (Rajkumar and Freitas, 2008; Jain and Sharma, 2015).

The increasing demand for natural polymers with industrial applications has thus led to an interest in EPS production by microorganisms which have high yield and better quality than plant or animal derived polysaccharides (Moscovici, 2015). In this article we report the screening of bacteria endophytic to $R$. communis $\mathrm{L}$. for production of EPS, determine the influence of nutritional and environmental conditions for EPS production by a selected potent strain under batch culture and characterization of the partially purified polymer.

\section{MATERIAL AND METHODS}

A total of 28 endophytic bacterial isolates of Ricinus communis L. used in the present study were isolated in the Microbiology Laboratory, Department of Botany, University of Calcutta. Pure cultures of endophytic bacterial isolates were maintained on slopes of nutrient agar by repeated sub-culturing at an interval of 30 days.

The selected potent EPS producing isolate was characterized following standard morphological and physiobiochemical tests (Gerhardt et al., 1994). Antibiotic sensitivity of the bacterial isolate was detected following the Kirby Bauer disc-diffusion assay (Bauer et al., 1966) using antibiotic impregnated discs (Himedia, India, $6 \mathrm{~mm}$ dia).

The 16S rRNA gene sequence of the isolate was determined by direct sequencing of PCR amplified 16S rDNA. The genomic DNA was isolated from the overnight grown culture and purified according to the modified method of Marmur (1961). The 16S rDNA was amplified using the universal primers 27F (5'AGAGTTTGATCCTGGCTCAG3') and 1492R (5'GGTTACCTTGTTACGACTT3') and the amplified product was purified using QIAquick gel extraction kit (Qiagen, Netherlands). The sequencing reaction was performed with ABI PRISM Dye Terminator cycle-sequencing ready reaction kit (Applied Biosystems) and products were purified and electrophoresed on polyacrylamide sequencing gel using an ABI 377 automated DNA sequencer. Sequencing data were analyzed by $A B I$ version 3.0.1 b3 software and compared with reference sequences using the NCBI BLASTN programme. Multiple sequence alignments were carried out by using BLOSUM 62 matrix with the program package Clustal$\mathrm{W}$ employing the neighbour-joining algorithm method (Saitou and Nei, 1987) with MEGA version 6.0.

Mineral salts medium was inoculated with freshly prepared inoculum $(2 \% \mathrm{v} / \mathrm{v})$ of the endophytic bacteria and incubated at $32{ }^{\circ} \mathrm{C}$ on rotary shaker $(120 \mathrm{rpm})$. Growth was determined by measuring dry weight of the washed cell mass harvested by centrifugation $\left(10,000 \times \mathrm{g}, 20{ }^{\circ} \mathrm{C}\right.$ for $10 \mathrm{~min})$. Cell pellet was transferred to pre-weighed aluminium cup and dried to constant weight at $80{ }^{\circ} \mathrm{C}$. The EPS of the cell-free culture filtrate was precipitated with double volume of chilled acetone, kept overnight at $4{ }^{\circ} \mathrm{C}$ and recovered by centrifugation $\left(12,000 \times \mathrm{g}, 4{ }^{\circ} \mathrm{C}\right.$ for $20 \mathrm{~min})$. Cell-bound EPS was extracted with EDTA $(0.05 \mathrm{M})$, precipitated with chilled acetone and recovered 
by centrifugation. The soluble and cell-bound EPS fractions were pooled and dissolved in known volume of distilled water prior to quantification.

The EPS was quantified following the phenol sulphuric acid method of Dubois et al. (1956). To $1 \mathrm{~mL}$ of EPS solution, $1 \mathrm{~mL}$ of $5 \%(\mathrm{w} / \mathrm{v})$ phenol solution was added and mixed thoroughly. To the reaction mixture, $5 \mathrm{~mL}$ of concentrated $\mathrm{H}_{2} \mathrm{SO}_{4}$ was purged in and the optical density was measured at $490 \mathrm{~nm}$ using Systronics colorimeter. The amount of EPS was determined from the calibration curve using glucose as the standard.

For isolation and purification of the EPS, the selected isolate RCR 08 was grown in mineral salts medium under continuous shaking for $64 \mathrm{~h}$. The cell-bound EPS was extracted following washing of cell mass with 0.05 M EDTA and separated by centrifugation $(12,000 \times \mathrm{g}$ for $20 \mathrm{~min}$ ). The EPS was recovered from the supernatant by precipitation with chilled acetone. The soluble EPS from the cell-free culture filtrate was obtained by the same acetone precipitation method. The soluble and bound EPS were pooled, dissolved in distilled water and subjected to dialysis in sterile water for $24 \mathrm{~h}$ at $4{ }^{\circ} \mathrm{C}$ with regular change of dialysate. On completion of dialysis, the EPS was further treated with chilled acetone at 4 ${ }^{\circ} \mathrm{C}$ and the precipitate was collected by centrifugation $\left(12,000 \times \mathrm{g}, 4{ }^{\circ} \mathrm{C}, 20 \mathrm{~min}\right)$ as partially purified EPS. To remove protein and nucleic acid, trichloroacetic acid (20\%) was added to the partially purified EPS solution and incubated in ice for 30 minutes prior to centrifugation $\left(15,000 \times \mathrm{g}, 4{ }^{\circ} \mathrm{C}, 30 \mathrm{~min}\right)$ (Bales et al., 2013). The supernatant was treated with double volume of chilled ethanol at $4{ }^{\circ} \mathrm{C}$ and the precipitate was collected by centrifugation $\left(12,000 \times \mathrm{g}, 4^{\circ} \mathrm{C}, 20 \mathrm{~min}\right)$.

The partially purified EPS was analyzed for its carbohydrate, protein and nucleic acid contents. While the carbohydrate content was estimated following the phenol-sulphuric acid method of Dubois et al. (1956), protein content was estimated by folin-phenol reagent using bovine serum albumin as standard (Lowry et al., 1951). DNA and RNA contents of the EPS were estimated by diphenylamine (Soni et al., 2011) and orcinol methods (Almog and Shirley, 1978) respectively.

The absorbance of the crude and purified EPS in distilled water was recorded in the range of 200 to $300 \mathrm{~nm}$ using UV-VIS spectrophotometer (Jenway, Model 6505).

The Fourier transform infrared (FTIR) spectra of the purified EPS were recorded in a Perkin Elmer RX-1 FTIR spectrometer. The dried sample was grinded with potassium bromide $(\mathrm{KBr})$ and pressed into pellet for spectrophotometric scanning in the frequency of 400 to 4000 $\mathrm{cm}^{-1}$.

The emulsification assay was carried out following the method as described by Cooper and Goldenberg (1987). The purified EPS solution (2.5 mL, 0.5\% w/v) was mixed with $2.5 \mathrm{~mL}$ hydrocarbons, vortexed to homogenity and left to stand for $24 \mathrm{~h}$ at $4{ }^{\circ} \mathrm{C}$. The emulsifying activity was expressed as the percentage of the total height occupied by the emulsion. The hydrocarbon substrates used were benzene, palm oil, olive oil, soybean oil, kerosene, petrol, octane, hexane, tetradecane and hexadecane.

The aqueous solution of purified EPS was filter sterilized and screened for antibacterial activity following agar-cup assay method using four test organisms like Escherichia coli, Bacillus subtilis, Staphylococcus aureus and Pseudomonas cepacia. Modified method of Liu et al. (2010) was used for the DPPH radical scavenging activity of the EPS. The reaction mixture containing $0.5 \mathrm{~mL}$ of purified EPS, $0.2 \mathrm{~mL}$ of DPPH solution (0.4 mM DPPH in methanol) and $2.5 \mathrm{~mL}$ distilled water was shaken vigorously, incubated for $30 \mathrm{~min}$ at room temperature and the optical density was measured at $517 \mathrm{~nm}$. Vitamin C (ascorbic acid) was used as the positive control. The percentage of scavenging of free radical was calculated according to the following formula:

$\%$ scavenging activity $=\left\{1-\left(\mathrm{A}_{1}-\mathrm{A}_{2} / \mathrm{A}_{0}\right)\right\} \times 100$

Where,

$\mathrm{A}_{1}=0 . \mathrm{D}$. of reaction mixture

$A_{2}=0 . D$. of reaction mixture without DPPH

$\mathrm{A}_{0}=0 . \mathrm{D}$. of reaction mixture with $\mathrm{DPPH}$ but without sample

Proliferation of Huh 7.5 cells in response to EPS produced by $B$. cereus RCR 08 was measured by using 3-(4,5-dimethylthiazol-2-yl)-2,5-diphenyltetrazolium bromide (MTT) assay as described by Slater et al. (1963). Huh 7.5 cells in DMEM medium were incubated overnight in 96 microtiter plate. The cells were treated with filter sterilized EPS of different concentrations and incubated for $48 \mathrm{~h}$ following an additional incubation of $4 \mathrm{~h}$ with $20 \mu \mathrm{L}$ of MTT $(5 \mathrm{mg} / \mathrm{mL})$. The MTT-transformed crystals were dissolved in MTT solvent [4 mM $\mathrm{HCl}, 0.1 \%$ Nondet P-40 (NP40) in isopropanol] and the absorbance was measured at $595 \mathrm{~nm}$ with a reference filter of $620 \mathrm{~nm}$ by using a microplate reader (Molecular Devices, Sunnyvale, USA). The relative cell viability was expressed as the mean percentage of viable cells relative to the respective control.

All experiments were carried out in triplicates and results represent mean \pm standard deviation.

\section{RESULTS AND DISCUSSIONS}

Endophytic microorganisms, the bacteria in particular have long been recognized as important bioresources for production of structurally and functionally diverse extracellular polymeric substances. All 28 endophytic 


\begin{tabular}{|c|c|c|}
\hline $\begin{array}{l}\text { Category of } \\
\text { producer }\end{array}$ & $\begin{array}{l}\text { Production of } \\
\text { EPS, g/L }\end{array}$ & $\begin{array}{l}\text { \% EPS } \\
\text { producer* }\end{array}$ \\
\hline Good & $>1.0$ & 3.57 \\
\hline Moderate & $0.31-1.0$ & 85.71 \\
\hline Poor & $0.14-0.3$ & 10.71 \\
\hline
\end{tabular}

bacteria isolated from Ricinus communis L. were screened for EPS production during growth under batch cultivation in glucose containing mineral salts medium. The EPS content (bound and free) of each isolate was quantified in terms of their carbohydrate content (Dubois et al., 1956) and almost all the endophytic isolates of $R$. communis L. were capable of producing EPS (Table 1). Majority of the isolates were poor to moderate producers with the exception of isolate RCR 08, which produced good amount of EPS (1.5 g/L) and was selected for further studies. Liu et al. (2017) in a recent review have summarized the EPS-producing endophytic bacteria and their host plants which include rice, sorghum, sugarcane, Artimisia annua, Ophiopogon japonicas, etc.

Morphological and physiological analysis revealed that the endophytic isolate RCR 08 endophytic to root tissues of $R$. communis L. is a rod-shaped, Gram-positive, motile and endospore forming bacterium which form white smooth colonies on mineral salts agar (Figure 1). The isolate could tolerate wide range of $\mathrm{pH}$ (3.5-8.0) and temperature $\left(30-40{ }^{\circ} \mathrm{C}\right.$ ) and produced a number of hydrolytic enzymes such as catalase, amylase, protease, pectinase, lipase, gelatinase and inulinase. It produced acid from glucose, fructose, sucrose, maltose and galactose and was resistant to antibiotics ampicillin, bacitracin, penicillin and methicillin. Based on these characteristics, the endophytic isolate RCR 08 was tentatively identified as a member of the genus Bacillus. Sequence analysis of $16 \mathrm{~S}$ rDNA of the isolate Bacillus RCR 08 showed 99\% similarity with Bacillus cereus strain ATCC

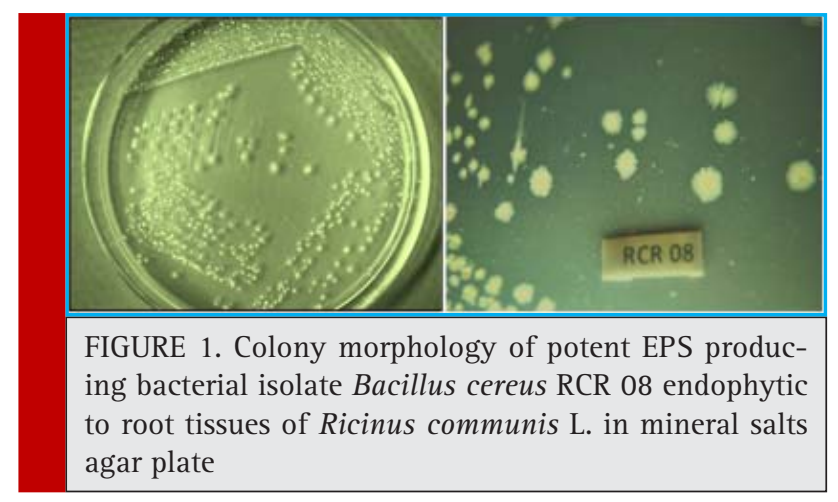

14579, reasonably high score and e-value being zero. The evolutionary relationship of the endophytic isolate RCR 08 as depicted from the dendrogram showed clear rooted evolution (Figure 2). The 16S rDNA sequence of the isolate RCR 08 has been deposited to the GenBank under the accession number MF159112 and the isolate has been designated as Bacillus cereus RCR 08. Similar to $B$. cereus RCR 08, production of EPS by B. cereus SZ1 endophytic to Artimisia annua L. is not uncommon (Zheng et al., 2016). Likewise endophytic B. amyloliquefaciens (Chen et al., 2013) and B. licheniformis (Singh et al., 2011) isolated from Ophiopogon japonicas and Gracilaria dura respectively are well recognized as EPS producers.

The production of EPS by bacteria in culture depends on phases of growth, media components, nutritional status and the environmental conditions. Media components including carbon and nitrogen sources, mineral elements, etc. on EPS production have been tested using the single factor method. Out of eight different media tested, $B$. cereus RCR 08 showed maximum EPS production $(7.65 \mathrm{~g} / \mathrm{L})$ in ammonium chloride containing mineral salts medium (Table 2). Yeast extract medium supported significant biomass formation but not the EPS production. Tryptic soy and Luria Bertani media failed to support both biomass as well as EPS production by $B$. cereus RCR 08.

During growth under shake flask condition in mineral salts medium, the extracellular polymer accumulation by the endophytic isolate $B$. cereus RCR 08 was found to be more or less parallel with growth and continued to increase till late stationary phase of growth. The highest EPS production (9.48 g/L) was obtained after $64 \mathrm{~h}$ of incubation (Figure 3). This supports the earlier observations of Decho (1990) and Manca et al. (1996). EPS synthesis was accompanied by increasing cell mass formation until glucose, the sole source of carbon, was consumed. In addition, production of EPS was accompanied with decline of $\mathrm{pH}$ of the medium (data not shown).

Ability to utilize nine different carbon sources for growth and EPS production by $B$. cereus RCR 08 was tested and EPS production was highest $(9.48 \mathrm{~g} / \mathrm{L})$ in glucose followed by mannitol (6.93 g/L) and maltose (5.07 $\mathrm{g} / \mathrm{L}$ ) (Figure 4). Though, the isolate B. cereus RCR 08 preferred maltose for growth, it failed to utilize galactose. Different carbon sources have been utilized for EPS production by endophytes (Liu et al., 2009; Bragadeeswaran et al., 2011) and glucose and sucrose are reported to be the most suitable ones.

Recently, Li et al. (2016) and Mahapatra and Banerjee (2016) have showed that organic nitrogenous compounds supported higher biomass and EPS yield than the inorganic ones. Supplementation of both inorganic and organic nitrogen in the growth medium at $0.1 \%(\mathrm{w} / \mathrm{v})$ 


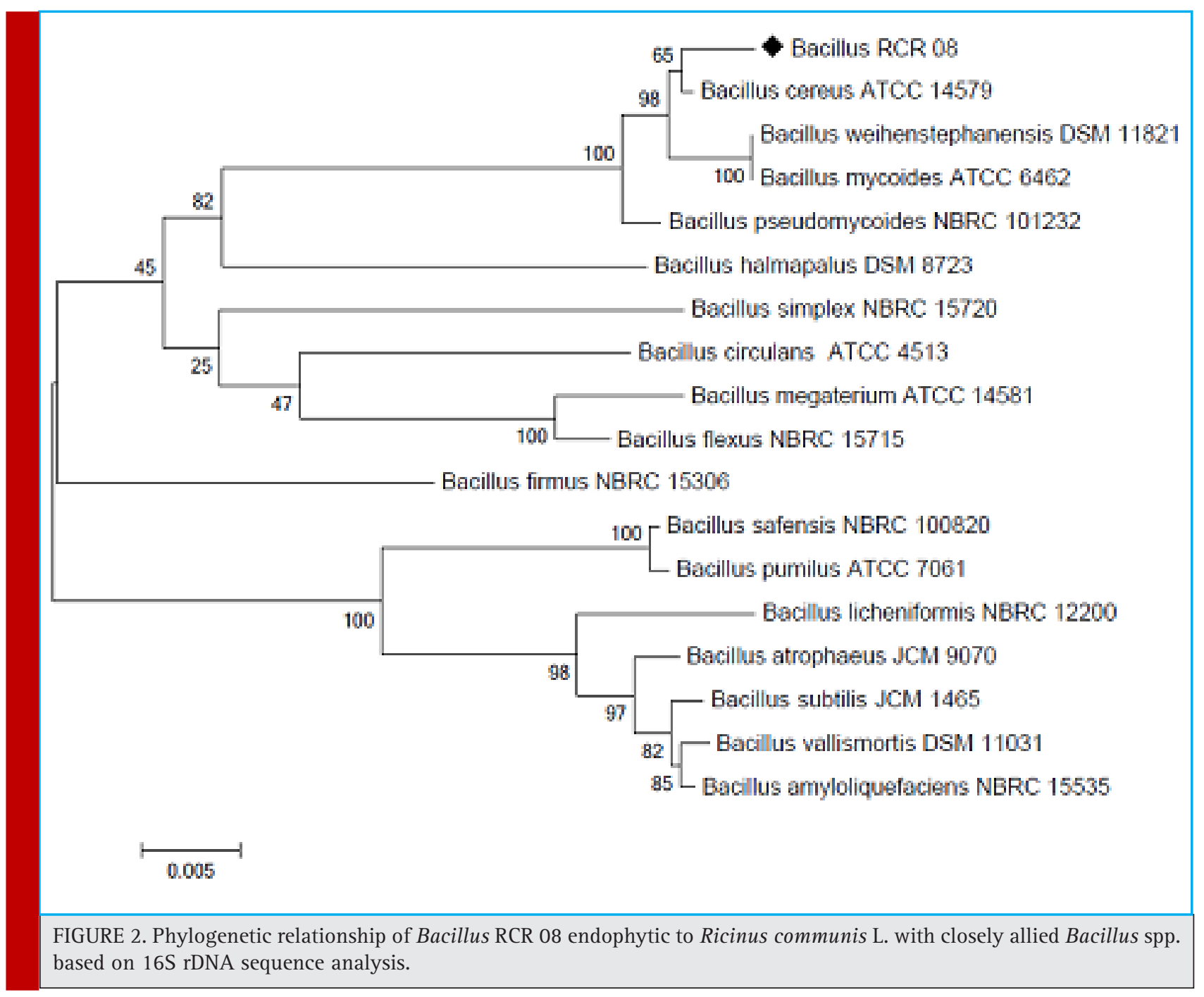

Table 2. Effect of different media on growth and EPS production by the endophytic bacterial isolate B. cereus RCR 08

\begin{tabular}{|l|l|l|l|l|}
\hline \multirow{2}{*}{ Medium } & \multicolumn{2}{|c|}{ Growth, CDW, g/L } & \multicolumn{2}{c|}{ EPS, g/L } \\
\cline { 2 - 5 } & $48 \mathrm{~h}$ & $\mathbf{7 2} \mathrm{h}$ & $\mathbf{4 8} \mathrm{h}$ & $\mathbf{7 2} \mathrm{h}$ \\
\hline Davis and Mingioli's medium & $1.4 \pm 0.02$ & $2.4 \pm 0.02$ & $2.09 \pm 0.04$ & $1.81 \pm 0.03$ \\
\hline Mineral salts medium & $1.6 \pm 0.01$ & $1.9 \pm 0.04$ & $1.05 \pm 0.03$ & $1.38 \pm 0.04$ \\
\hline Mineral salts medium with NH4Cl & $6.7 \pm 0.04$ & $6.4 \pm 0.03$ & $6.07 \pm 0.05$ & $7.65 \pm 0.07$ \\
\hline Glutamate-mannitol medium & $4.0 \pm 0.02$ & $4.0 \pm 0.03$ & $1.36 \pm 0.04$ & $2.13 \pm 0.04$ \\
\hline Tris-Glucose medium & $1.8 \pm 0.01$ & $2.0 \pm 0.02$ & $1.65 \pm 0.02$ & $1.90 \pm 0.02$ \\
\hline Yeast extract medium & $4.7 \pm 0.03$ & $4.5 \pm 0.01$ & $2.94 \pm 0.03$ & $3.75 \pm 0.02$ \\
\hline Tryptic soy medium & $4.6 \pm 0.03$ & $4.5 \pm 0.03$ & $1.06 \pm 0.03$ & $1.41 \pm 0.04$ \\
\hline Luria Bertani medium & $3.4 \pm 0.01$ & $2.8 \pm 0.04$ & $1.73 \pm 0.02$ & $1.19 \pm 0.02$ \\
\hline Values represent mean of triplicate readings \pm S.D. & \multicolumn{4}{|l}{} \\
\hline
\end{tabular}



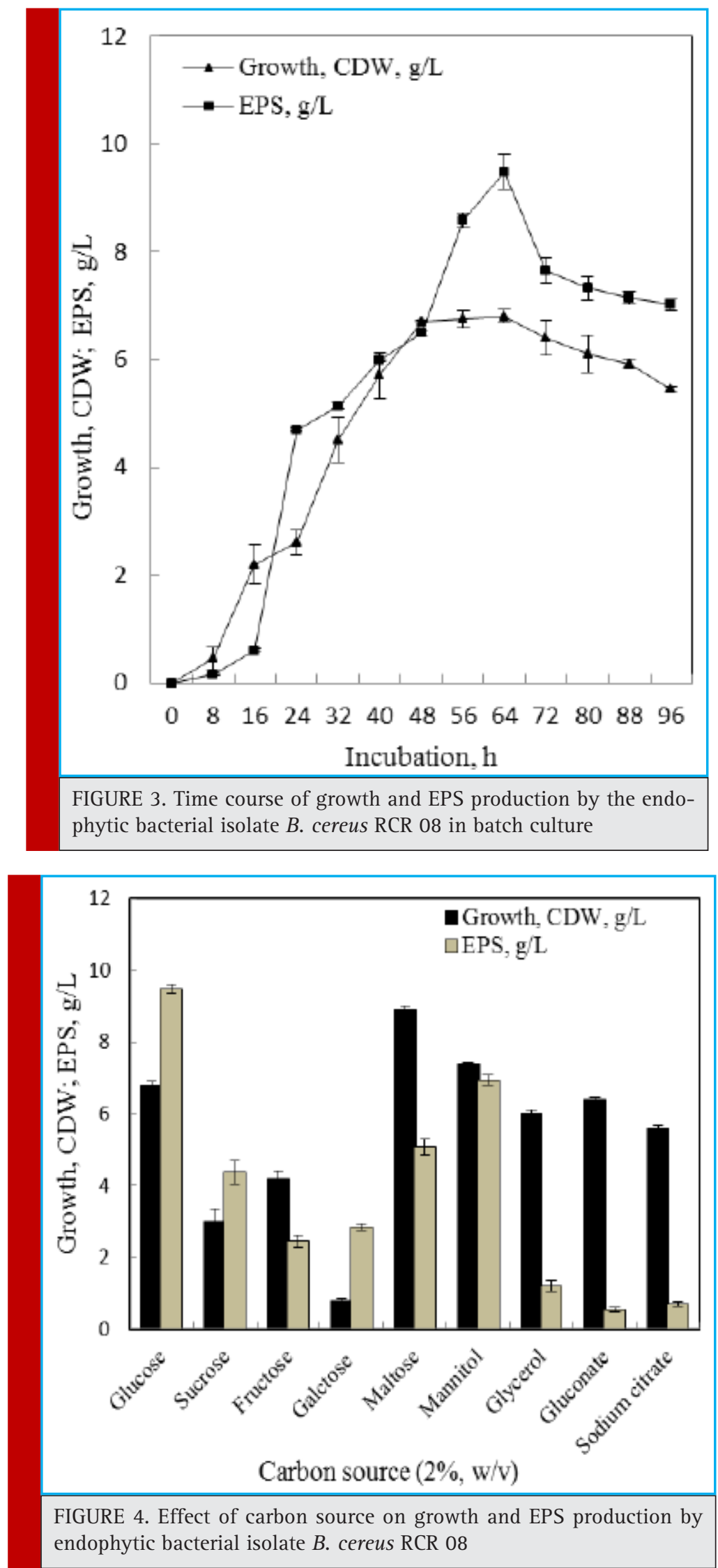


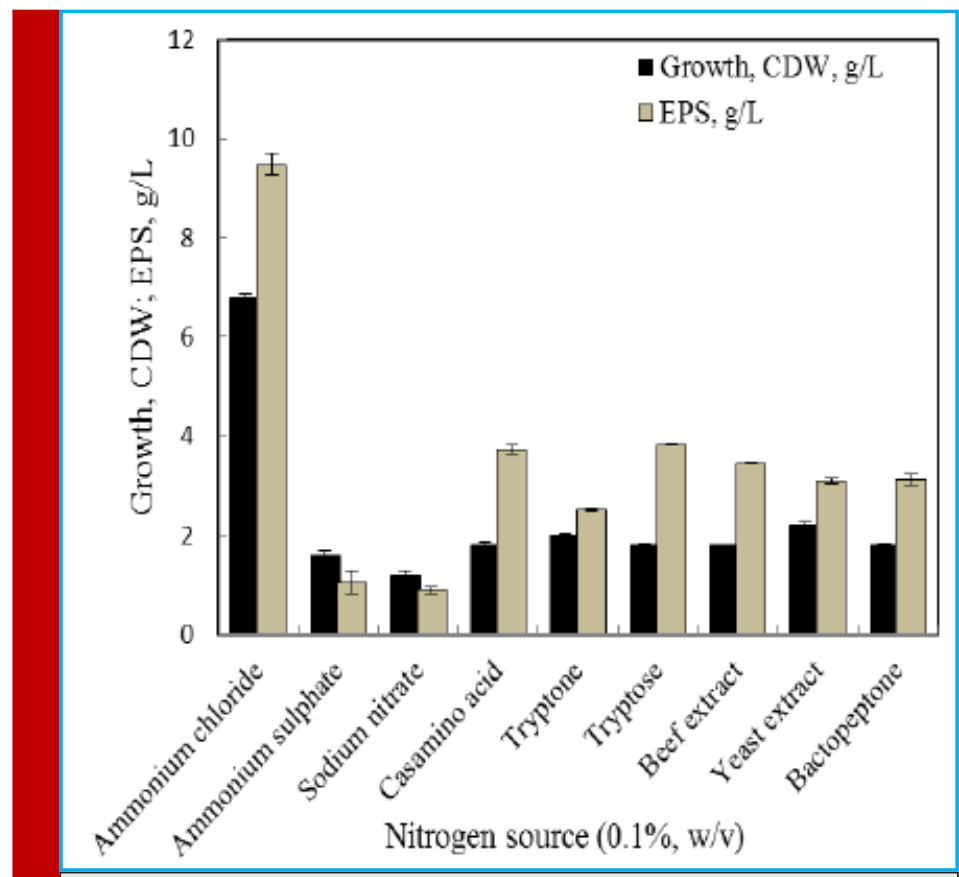

FIGURE 5. Effect of nitrogen source on growth and EPS production by the endophytic bacterial isolate $B$. cereus RCR 08

level showed discrete variation in the growth and polymer production by the isolate $B$. cereus RCR 08, however maximum EPS production $(9.48 \mathrm{~g} / \mathrm{L}$ ) was recorded in presence of ammonium chloride and was followed by organic nitrogenous compounds such as tryptone, casamino acid and beef extract (Figure 5). When glucose and ammonium chloride in the medium were maintained at a ratio of 25:1 maximum growth $(7.1 \mathrm{~g} / \mathrm{L})$ and EPS production (10.24 g/L) were recorded (Figure 6).

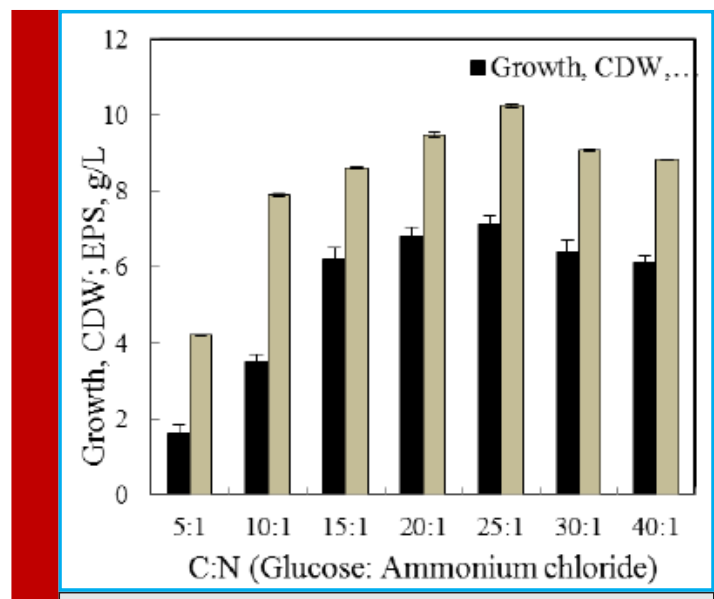

FIGURE 6. Effect of C:N (glucose: ammonium chloride) ratio on growth and EPS production by the endophytic bacterial isolate $B$. cereus RCR 08
Miqueleto et al. (2010) studied the influence of different carbon sources and the $\mathrm{C} / \mathrm{N}$ ratio on the production of EPS by immobilized bacterial biomass and found that high $\mathrm{C} / \mathrm{N}$ ratio favored the biopolymer production.

Compositional analysis of the partially purified EPS of $B$. cereus RCR 08 revealed that it was composed of $88.8 \%$ carbohydrate, $3.18 \%$ protein, $6.0 \%$ RNA as well as $3.2 \%$ DNA. The partially purified EPS showed characteristic peaks of protein and nucleic acids at 260 and 280 nm, respectively (Figure 7). Following TCA treatment, the EPS, however showed characteristic spectrum similar to those of authentic polysaccharides such as galactan and dextrin (Figure 7).

FTIR spectrum of purified EPS showed characteristic absorption peaks at 3404, 2,933, 1,655, and 1,042 $\mathrm{cm}^{-1}$ (Figure 8). The strong band at $3404 \mathrm{~cm}^{-1}$ was assigned to the hydroxyl stretching vibration of the polysaccharide, while the band at $2933 \mathrm{~cm}^{-1}$ was due to $\mathrm{C}-\mathrm{H}$ stretching vibration. The bands in the region of 1500 and 1200 $\mathrm{cm}^{-1}$ were assigned to $\mathrm{C}-\mathrm{H}$ deformation vibration and the bands between 1100 and $1075 \mathrm{~cm}^{-1}$ corresponded to $\mathrm{C}-\mathrm{O}-\mathrm{C}$ and $\mathrm{C}-\mathrm{O}-\mathrm{H}$ stretching vibration. A characteristic absorption at $928 \mathrm{~cm}^{-1}$ was possibly due to the stretching vibration of pyran ring (Liu et al., 2010). A similar spectrum was also observed by Sonawdekar and Gupte (2016) for EPS from B. cereus.

The emulsifying activity of extracellular polysacharides as tested by the method of Cooper and Goldenberg (1987) revealed that all the hydrocarbons (except petrol and hex- 


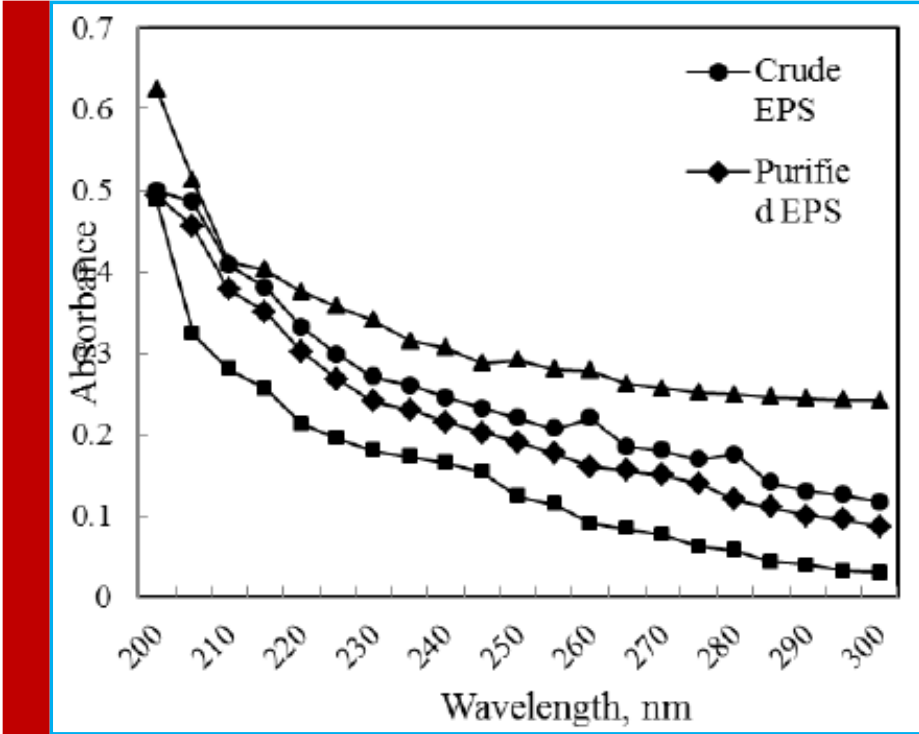

FIGURE 7. Comparision of UV absorption spectra of the purified exopolysaccharide obtained from the endophytic bacterial isolate $B$. cereus RCR 08 with other authentic polysaccharides

adecane) showed effective emulsification (Table 3). The highest emulsifying activity of the EPS was obtained with benzene $(76.37 \%)$ followed by tetradecane $(70 \%)$ and hexane (66.66\%). However, tween 80 showed higher emulsifying activity for kerosene (73.07\%) than the EPS of B.cereus RCR 08. Chowdhury et al. (2011) reported high emulsifying activity of $B$. megaterium RB-05 EPS in coconut oil, mustard oil and xylene while $B$. cereus isolated by Sonawdekar and Gupte (2016) showed 53\% emulsification.

Though there are several reports of EPS with antimicrobial activities (Orsod et al., 2012), the EPS produced by the endophytic isolate RCR 08 failed to show any antibacterial activity when tested against $E$. coli, B. subtilis, S. aureus and P. cepacia by agar-cup assay. Similarly, antioxidant properties of EPS (Liu et al., 2009) are also not rare. The DPPH radical scavenging activity of the EPS isolated from $B$. cereus RCR 08 increased with increasing concentrations and a scavenging activity of $16 \%$ was recorded at a concentration of $10 \mathrm{mg} / \mathrm{mL}$ but was much lower as compared to vitamin C (Figure 9). The scavenging activity exhibited by the EPS might be attributed due to their hydrogen donating abilities. The effect of EPS extracted from $B$. cereus RCR 08 on the viability of Huh 7.5 cells was determined by MTT assay.

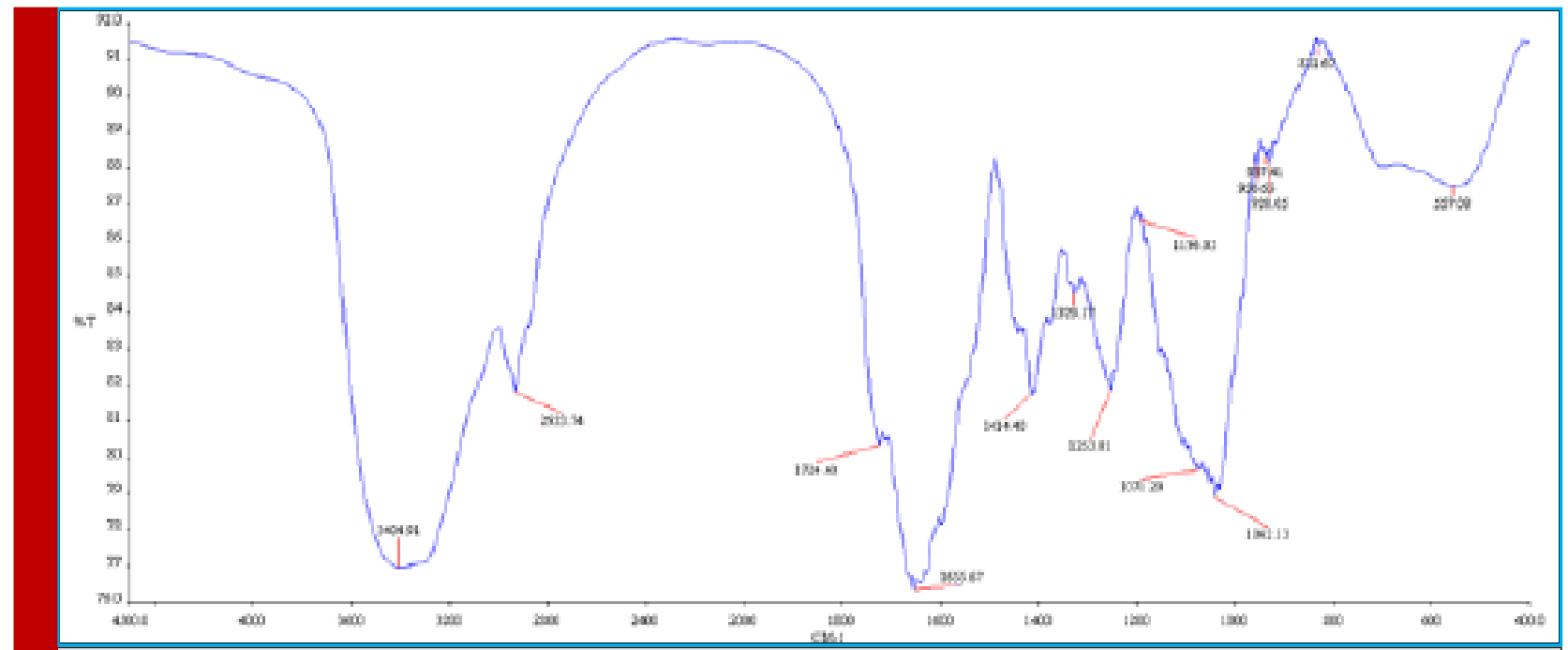

FIGURE 8. FTIR spectra of the purified EPS produced by the endophytic bacterial isolate $B$. cereus RCR 08 


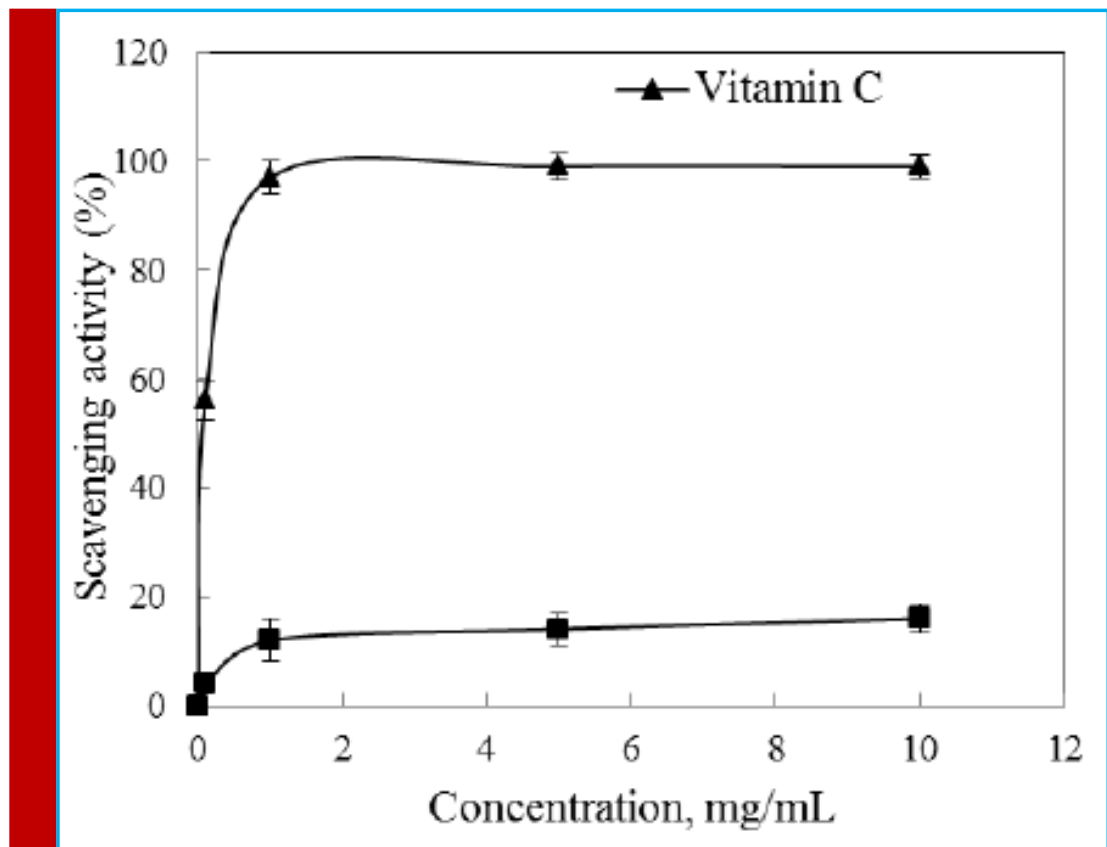

FIGURE 9. DPPH radical scavenging activity of the EPS produced by the endophytic bacterial isolate $B$. cereus RCR 08

The EPS displayed a dose-dependent cytotoxic activity against Huh 7.5 cell line in culture. The antiproliferative activity of the EPS gradually increased with increasing concentration. The EPS exhibited $60.8 \%$ viability of the
Huh 7.5 cells at a concentration of $2000 \mathrm{ng} / \mathrm{mL}$ (Figure 10). Li and Shah (2016) also reported strong antiproliferative activity of EPS isolated from Streptococcus thermophilus ASCC 1275 on Caco-2 and HepG2 cells.

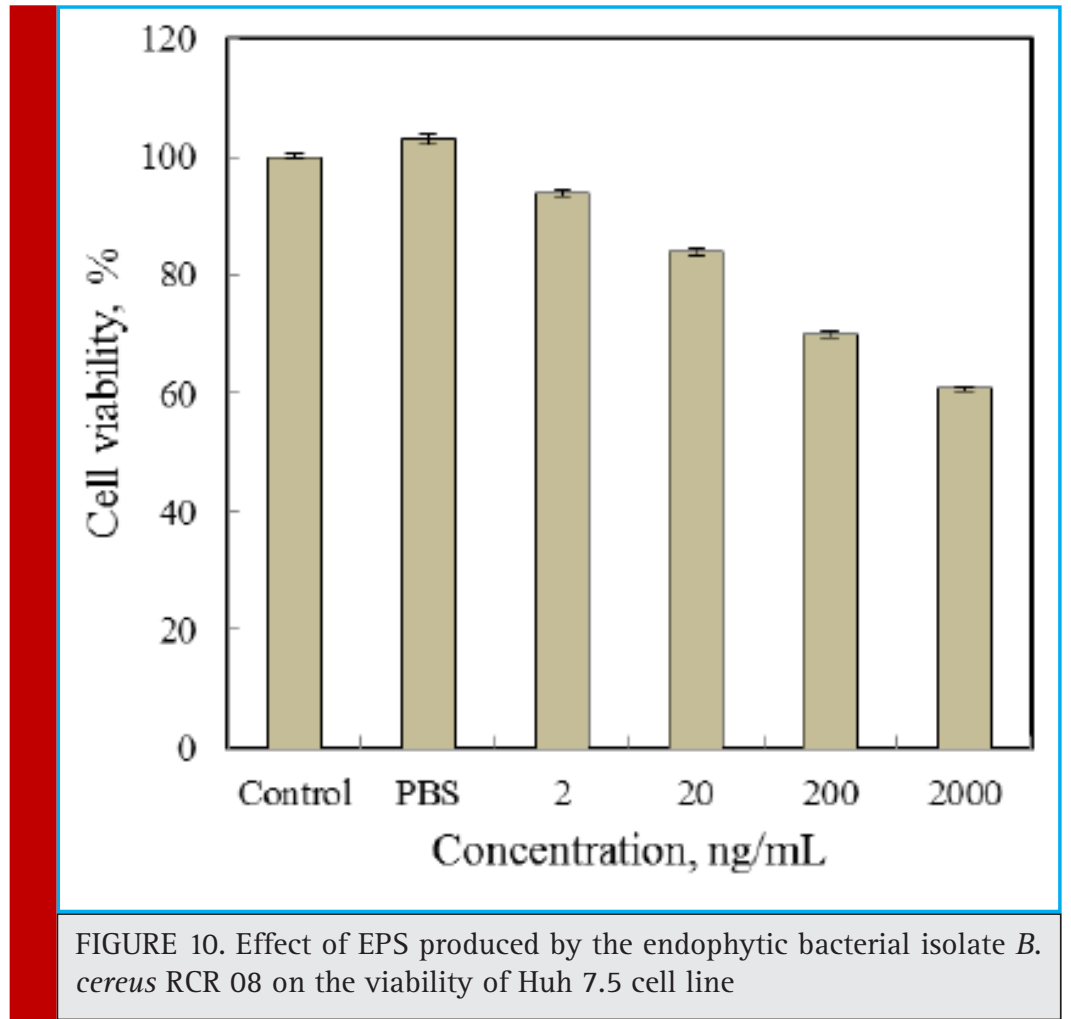




\begin{tabular}{|l|l|l|}
\hline \multirow{2}{*}{$\begin{array}{l}\text { Table 3. Emulsifying activity of EPS produced by } B . \\
\text { cereus RCR 08 and commercial emulsifier Tween } 80\end{array}$} \\
\hline \multirow{2}{*}{ Hydrocarbons } & \multicolumn{2}{|c|}{ Emulsification, \% } \\
\cline { 2 - 3 } & $\begin{array}{l}\text { EPS of B. cereus } \\
\text { RCR 08 }\end{array}$ & Tween $80^{*}$ \\
\hline Benzene & $76.37 \pm 2.50$ & $68.00 \pm 1.20$ \\
\hline Palm oil & $47.61 \pm 1.22$ & $48.00 \pm 1.22$ \\
\hline Olive oil & $60.00 \pm 1.25$ & $68.18 \pm 0.09$ \\
\hline Soybean oil & $63.15 \pm 1.23$ & $61.53 \pm 0.12$ \\
\hline Kerosene & $62.50 \pm 1.26$ & $73.07 \pm 0.08$ \\
\hline Petrol & - & $62.50 \pm 0.01$ \\
\hline Octane & $60.00 \pm 1.23$ & $68.00 \pm 0.00$ \\
\hline Hexane & $66.66 \pm 1.27$ & $64.00 \pm 0.15$ \\
\hline Tetradecane & $70.00 \pm 1.26$ & $61.23 \pm 0.12$ \\
\hline Hexadecane & - & $29.62 \pm 1.25$ \\
\hline $\begin{array}{l}\text { "Expressed as the percentage of the total height occupied by the oil } \\
\text { water emulsion after } 24 \text {; } \text {;each value represents the average of } \\
\text { three measurements } \pm \text { S.D. }\end{array}$ \\
\hline
\end{tabular}

\section{CONCLUSION}

Endophytes have been recognized as important sources of structurally and functionally novel extracellular polysaccharides which could find applications in medical, pharmaceuticals, chemical and other industries. The present study demonstrates that Bacillus cereus RCR 08, endophytic to Ricinus communis L., is capable of producing a substantial amount of extracellular polymeric substance employing a suitable carbon and nitrogen source in a definite ratio. Results so obtained appear to be beneficial for further assessment of enhancing the production of $B$. cereus RCR 08 EPS in large scale. The significant oil emulsifying activity along with antioxidant and antiproliferative activity against Huh 7.5 cell line deserve special attention. Thorough chemical analysis of these carbohydrate polymers is required to exploit them in pharmacy in adjunction to cancer trials.

\section{ACKNOWLEDGEMENTS}

This work was partially supported from the grant received by one of us (RD) from the Department of Science and Technology, New Delhi (Sanction No. DST-INSPIRE Fellowship/REL3/2013/2).

\section{CONFLICT OF INTEREST}

All authors have declared no conflicts of interest in this communication.

\section{REFERENCES}

Almog, R. and Shirley, T. L. (1978): A modified orcinol test for the specific determination of RNA. Ann Biochem. 91, 130-137.

Bales, P. M., Renke, E. M., May, S. L., Shen, Y. and Nelson, D. C. (2013): Purification and characterization of biofilm-associated EPS exopolysaccharides from ESKAPE organisms and other pathogens. PloS One. 8, e67950.

Bauer, A. W., Kirby, W. M. M., Sherris, J. C. and Turck, M. (1966): Antibiotic susceptibility testing by a standardized single disk method. Am J Clin Pathol. 36, 493-496.

Borges, W. D. S., Borges, K. B., Bonato, P. S., Said, S. and Pupo, M. T. (2009): Endophytic fungi: Natural products, enzymes and biotransformation reactions. Curr Org Chem. 13, 1137-1163.

Bragadeeswaran, S., Jeevapriya, R., Prabhu, K., Sophia Rani, S., Priyadharsini, S. and Balasubramanian, T. (2011): Exopolysaccharide production by Bacillus cereus GU812900, a fouling marine bacterium. Afr J Microbiol Res. 5, 4124-4132.

Chen, Y. T., Yuan, Q., Shan, L. T., Lin, M. A., Cheng, D. Q. and Li, C. Y. (2013): Antitumour activity of bacterial exopolysaccharides from the endophyte Bacillus amyloliquefaciens sp. isolated from Ophiopogon japonicas. Oncol Lett. 5, 1787-1792.

Chowdhury, S. R., Manna, S., Saha, P., Basak, R. K., Sen, R., Roy, D. and Adhikari, B. (2011): Composition analysis and material characterization of an emulsifying extracellular polysaccharide (EPS) produced by Bacillus megaterium RB-05: a hydrodynamic sediment-attached isolate of freshwater origin. J Appl Microbiol. 111, 1381-1393.

Cooper, D. G. and Goldenberg, B. G. (1987): Surface active agents from two Bacillus species. Appl Environ Microbiol. 53, 224-229.

Donot, F., Fontana, A., Baccou, J. C. and Schorr-Galindo, S. (2012): Microbial exopolysaccharides: Main examples of synthesis, excretion, genetics and extraction. Carbohydr Polym. 87, 951-962.

Dubois, M., Gilles, K. A., Hamilton, J. K., Rebers, P. A. and Smith, F. (1956): Calorimetric method for determination of sugars and related substances. Ann Chem. 28: 350-356.

Freitas, F., Alves, V. D. and Reis, M. A. (2011): Advances in bacterial exopolysaccharides: From production to biotechnological applications. Trends Biotechnol. 29, 388-398.

Gandhi, H. P., Ray, R. M. and Patel, R. M. (1997): Exopolymer production by Bacillus species. Carbohydr Polym. 34, 323-327.

Gerhardt, P., Murray, R. G. E., Wood, W. A. and Krieg, N. R. (1994): Methods for general and molecular bacteriology. Washington DC: American Soceity for Microbiology.

Guo, S., Mao, W., Yan, M., Zhao, C., Li, N., Shah, J., Lin, C., Liu, X., Guo, T. and Wang, S. (2014): Galactomannan with novel structure produced by the coral endophytic fungus Aspergillus ochraceus. Carbohydr Polym. 105, 325-333.

Jain, P. and Sharma, P. (2015): Isolation and preliminary screening of endophytic fungi of Ricinus communis for their antimicrobial potential. J Microbiol Biotech Food Sci. 5, 230233. 
Kusari, S., Singh, S. and Jayabaskaran, C. (2014): Biotechnological potential of plant-associated endophytic fungi: Hope versus hype. Trends Biotechnol. 32, 297-303.

Li, S. and Shah, N. P. (2016): Characterization, antiInflammatory and antiproliferative activities of natural and sulfonated exo-polysaccharides from Streptococcus thermophilus ASCC 1275. J Food Sci. 81, 1167-1176.

Li, Y., Guo, S. and Zhu, H. (2016): Statistical optimization of culture medium for production of exopolysaccharide from endophytic fungus Bionectria ochroleuca and its antitumour effect in vitro. EXCLI J. 15, 211-220.

Liu, J., Luo, J., Ye, H., Sun, Y., Lu, Z. and Zeng, X. (2009): Production, characterization and antioxidant activities in vitro of exopolysaccharides from endophytic bacterium Paenibacillus polymyxa EJS-3. Carbohydr Polym. 78, 275-281.

Liu, J., Luo, J., Ye, H., Sun, Y., Lu, Z. and Zeng, X. (2010): Medium optimization and structural characterization of exopolysaccharides from endophytic bacterium Paenibacillus polymyxa EJS-3. Carbohydr Polym. 79, 206-213.

Liu, J., Wang, X., Pu, H., Liu, S., Kan, J. and Jin, C. (2017): Recent advances in endophytic exopolysaccharides: Production, structural characterization, physiological role and biological activity. Carbohydr Polym. 157, 1113-1124.

Lowry, O. H., Rosebrough, N. J., Farr, A. L. and Randall, R. J. (1951): Protein Measurement with the Folin Phenol Reagent. J Biol Chem. 193, 265-275.

Mahapatra, S. and Banerjee, D. (2016): Production and structural elucidation of exopolysaccharide from endophytic Pestalotiopsis sp. BC55. Int J Biol Macromolec. 82, 182-191.

Manca, M. C., Lama, L., Improta, R., Esposito, A., Gambacorta, A. and Nicolaus, B. (1996): Chemical composition of two exopolysaccharides from Bacillus thermoantarcticus. Appl Environ Microbiol. 62, 3265-3269.

Miqueleto, A. P., Dolosic, C. C., Pozzi, E., Foresti, E. and Zaiat, M. (2010): Influence of carbon sources and C/N ratio on EPS production in anaerobic sequencing batch biofilm reactors for wastewater treatment. Bioresour Technol. 101, 1324-1330.

Moscovici, M. (2015): Present and future medical applications of microbial exopolyssaccharides. Front Microbiol. 6, 1012.
Orsod, M., Joseph, M. and Huyop, F. (2012): Characterization of exopolysaccharides produced by Bacillus cereus and Brachybacterium sp. Isolated from Asian Sea Bass (Lates calcarifer). Malaysian J Microbiol. 8, 170-174.

Rajkumar, M. and Freitas, H. (2008): Influence of metal resistant-plant growth-promoting bacteria on the growth of Ricinus communis in soil contaminated with heavy metals. Chemosphere. 71, 834-842.

Saitou, N. and Nei, M. (1987): The neighbor-joining method: A new method for reconstructing phylogenetic trees. Mol Biol Evol. 4, 406-425.

Singh, R. P., Shukla, M. K., Mishra, A., Kumari, P., Reddy, C. R. K. and Jha, B. (2011): Isolation and characterization of exopolysaccharides from seaweed associated bacteria Bacillus licheniformis. Carbohydr Polym. 84, 1019-1026.

Slater, T. F., Sawyer, B. and Strauh, U. (1963): Studies on succinatetetrazolium reductase system. Ill. Points of coupling of four different tetrazolium salts. Biochem Biophys Acta. 77, 383393.

Sonawdekar, S. and Gupte, A. (2016): Production and characterization of exopolysaccharide produced by oil emulsifying bacteria. Int J Curr Microbiol App Sci. 5, 254-262.

Soni, H., Singhai, A. K., Swarnkar, P., Sharma, S. and Kumar, V. (2011): Spectrophotometric method for quantitative estimation of DNA isolated from various parts of Catharanthus roseus. Int J Pharm Pharm Sci. 3, 529-532.

Sutherland, I. W. (1998): Novel and established applications of microbial polysaccharides. Trends Biotechnol. 16, 41-46.

Wingender, J., Neu, T. R. and Flemming, H. C. (1999): What are bacterial extracellular polymer substances. In: Microbial Extracellular Polymer Substances. Springer, Berlin, pp. 1-19.

Yamada, T., Ogamo, A., Saito, T., Watanabe, J., Uchiyama, H. and Nakagawa, Y. (1997): Preparation and anti-HIV activity of low-molecular-weight carrageenans and their sulfated derivatives. Carbohydr Polym. 32, 51-55.

Zheng, L. P., Zou, T., Ma, Y. J., Wang, J. W. and Zhang, Y. Q. (2016): Antioxidant and DNA damage protecting activity of exopolysaccharides from the endophytic bacterium Bacillus cereus SZ1. Molecules. 21, 174. 